\title{
UNITED STATES BUREAU OF STANDARDS
}

\begin{abstract}
1963 Research Highlights is the title of the detailed annual report for the year onding December 31 , 1963 , of the activities of the National Bureau of Standards*. The director, A. V. Astin, is assisted by two deputy directors and three associate directors. One deputy director is responsible for basic standards and services, and the other for technological standards and services. New laboratories for the Bureau are under construction at Gaithersburg, Maryland, and one of the associate directors is primarily responsible for the transfer which will shortly take place. The Bureau consists of twenty-four scientific divisions, sixteen of which are at present located in Washington. The remainder constitute the Boulder Laboratories in Boulder, Colorado, which are under the management of R. B. Scott. The total staff of the Bureau numbers about 4,160 , of whom some 1,450 are professional physicists, chemists, engineers and mathematicians, and 200 rescarch associates and guest workers. The 1963 programme cost 59 million dollars, and was financed by grants from Congress, payments for specific research and development tasks, and payments by industrial concerns, universities, research institutions and Government agencies for calibrating and testing services.
\end{abstract}

The report consists of a general review of the Bureau's activities, followed by more detailed reports of the research programmes of the individual divisions arranged so as to bring together related types of activity. In the metrological section, it is reported that a new standard of irradiance has been developed. This consists of a $200-\mathrm{W}$ quartz-iodine lamp with a coiled-coil tungsten filament operating at about $3,000^{\circ} \mathrm{K}$, no auxiliary optics being required. In order to calibrate standards to $10^{-7} \mathrm{in}$. an ellipsometer was used to determine the thickness of the molecular film between gauge blocks when in contact as the film becomes an inherent part of the length standard. The lenses of the 26-in. refracting telescope at the University of Virginia were tested in situ by a wave-front shearing interferometer placed at the focus of the telescope, and by applying the $11,530 \AA$ infra-red light produced by a helium-neon gas laser to a modified Michelson interferometer fringes were produced which when converted to visible wave-lengths were observed and photographed over a $200-\mathrm{m}$ optical path. The freezing pressure of mercury at $0^{\circ} \mathrm{C}$ was determined, and the value obtained, $109,722 \pm 30 \mathrm{lb} . /$ in. $^{2}$, indicates that this can serve as a calibration fixed point in high-pressure measurement. For the measurement of low pressures, a detailed investigation of capillarity effects on the McLeod gauge has been made, and a search is being undertaken for suitable force. per-unit area techniques to replace the more conventional indirect methods of measurement.

A number of advances in the field of electrical measurement are announced. To meet the need for greater speed and accuracy in the determination of a.c. voltages at audiofrequencies a new d.c.-a.c. comparator was developed and a usable procision of 10 parts per million attained. A permanent adjustable standard of magnetic susceptibility, formed by using the magnetic equivalence of a uniformly polarized volume of paramagnetic material and a solenoid carrying an electric current, was incorporated into a magnetic susceptibility bridge of high accuracy and sensitivity. A new cæsium beam frequency standard, 'NBS-3', was completed, its spectral line width being less than half that of 'NBS-2'. The 'NBS-1' cæsium beam was

* United States Department of Commerce: National Bureau of Standards. Miscellaneous Publication No. 255: 1963 Research Highlights of the National Bureau of Standards, Annual Report, Fiscal Year, 1963. P.
(Washington, D.C.: Government Printing Office, 1963.) 1 doliar. converted into a thallium beam and approximately the same precision as previously was obtained. In the field of quantum electronics, investigations included the measurement of the velocity of $\gamma$-rays by means of the Mössbauer effect, the determination of the fine structure constant using singly ionized helium, and the exarnination of the mechanisms by which blue fluorescence may be induced in anthracene using the red light of a pulsed ruby laser.

The comprehensive programme of research on the thermodynamic properties of simple light-element compounds important in rocket propulsion was continued. The low-temperature heat-capacity data of some 80 substances taken from the literature were analysed by means of a computer and the thermal functions determined. A computer programme which requires no 'manual' operation is now being developed. The Bureau has continued to act as the world centre for the collection and determination of most of the atomic physics data needcd particularly by plasma and astrophysicists. Emphasis has centred on the observation and analysis of the spectra of the rare-earths. A new edition of the cxtensive solar spectrum is near completion. From an analysis under high resolution of the infra-red spectrum of carbon suboxide $\left(\mathrm{C}_{3} \mathrm{O}_{2}\right)$ conclusive evidence has now becn obtained that the molecule is a straight chain consisting of three carbon atoms with an oxygen atom at either end.

The solid-state physics programme of measurements of electronic transport, optical characteristics, magnetic resonance and dielectric properties has been supported by theoretical investigations and by crystal growth and structural investigations. The main emphasis was on Ti-O compounds, CdTe, $\mathrm{PbF}_{2}$ and several azides. Measurements of the Seebeck coefficients of $\mathrm{TiO}_{2}$ and $\mathrm{SrTiO}_{3}$ down to $15^{\circ} \mathrm{K}$ have shown that the phonon-drag effect contributes most to the coefficient of rutile at low temperatures, but is almost absent in $\mathrm{Sr}^{\prime} \mathrm{TiO}_{3}$. Good crystals of CdTe were grown by the Bridgman method. Argon and krypton erystals were grown at temperatures near their triple points, $84^{\circ} \mathrm{K}$ and $116^{\circ} \mathrm{K}$, respectively, and the properties and growth characteristics of these gaseous crystals, which can be regarded as prototype molecular solids, were found to accord closely with those predicted by theory.

The 100-MeV linear accelerator (Linac) and the 1.5and $4-\mathrm{MeV}$ direct accelerators, which are to become operational during 1964 and are housed at Craithersberg, will enable the Bureau to meet the increased demands for basic experimental data, improved standards and refined measurement techniques in radiation physics. A broad programmo of basic research in physical chemistry is carried out by the Bureau. This covers the kinctics of very fast reactions at high temperatures, the photosynthesis of labelled organic molecules, the structure of reactive molecules, surface catalysis, and the interaction of highenergy radiation with organic molecules.

Metal fatigue in aluminium alloys, deformation of metals at low temperatures, anisotropic effects in a series of lead-iridium alloys, the kinetics of metal whisker growth from the vapour phase, electrocrystallization, and the Peltier effect at liquid junctions are some of the iterns discussed in the metallurgy section. Other sections deal with investigations carried out on natural and synthetic polymers, radio propagation including ionospheric, tropospheric and satellite communication, cryogenic engineering, building research, mathematical processes including machine translation. computer facilities and data processing systems. 
During the year under review 1,122 papers and documents were published and in addition some 420 classified and unclassified reports were issued to Government agencies. A comprehensive list of these is given in the appendix to the report. The periodicals published by the Bureau include Journal of Research, which is issued in four separate sections-A (Physics and Chemistry) bimonthly, B (Mathematics and Mathematical Physics) quarterly; $\mathrm{C}$ (Engineering and Instrumentation) quarterly; D (Radio Propagation) bimonthly-and Technical News Bulletin, which is a monthly in which present-day research, development and test activities of the Bureau are summarized. In addition, various non-periodical series publications, the Monograph, Handbook, Miscellaneous Publications, and Technical Notes series, are issued at frequent intervals. Monograph No. 56, Systems of Electrical Units, by F. B. Silsbee, is an excellent survey of the various systems of units used in electricity and traces briefly their historical development. Tensile and Impact Properties of Selected Materials from $20^{\circ} \mathrm{K}$ to $300^{\circ} K$ (Monograph No. 63) is concerned with structural materials for use in low-temperature applications, and data relating to their tensile strength, yield strength, elongation, stress-strain curves, and impact properties are given. Standard X-ray Diffraction Powder Patterns (Monograph 25 ) is the twelfth in the series with this title and contains 37 standard patterns of value to chemists in the identification of unknown crystalline materials.

A 16-mm colour film, Scatter Radar: Space Research from the Ground, released during 1963, tells the story of the Bureau's new Jicmarca Observatory situated near Lima, Peru. The Observatory has a 22 -acre radar aerial and is used to measure at $50 \mathrm{Mc} / \mathrm{s}$ the characteristics of ionization in the ionosphere and exosphere. It has made observations of the planet Venus, and will investigate the solar corona and solar gases. The Bureau participated in 18 scientific and technological exhibitions, and as part of the sixtieth anniversary celebrations of the Department of Commerce the Burcau's Washington laboratories were opened to the public for the first time for many years on May 11, 1963. Some 7,000 visitors toured the 100 laboratories and saw the special exhibits on display.

S. WeINTROUH

\section{ROAD RESEARCH}

$I^{N}$ N recommending that the Road Research Laboratory should be transferred to the proposed Industrial Research and Development Authority, the Trend Committee had reservations as to whether the arrangement should be permanent and suggested that the position should be reviewed after a reasonable interval, with the view of the possible transfer of the management of the Station to the Ministry of Transport. This would be in line, with present-day opinion for the strengthening of the scientific resources within the several Departments, but in spite of this the Road Research Report Board in its annual report for $1963^{*}$ expresses the emphatic view that the value of the Laboratory's research is enhanced by its independence and by the fact that it is seen to be independent by the public and the many authorities and other bodies who benefit from its work. It regards the Laboratory as carrying out its task with conspicuous success within the limits of its resources, but it should be noted that it does not consider that it is the function of a research organization, or within its competence, to apply the results itself, although it admits that a research organization must accept some responsibility for effectively disseminating the results of its researches. The Board reiterates a recommendation it made early in the year, as to the importance that plans should provide for the large staff that will bo needed in the near future in view of the great increase forecast for road traffic and road building. The Board welcomes the Laboratory's concern with research on road casualties and urges that prompt action should be taken to apply such measures as research has shown to be appropriate to diminish this continuing lose of life and limb. On lighting problems, in view of the demonstration by the Laboratory's investigations that the accident rate is greater at night than by day and that effective street lighting appreciably reduces the night accident figures, it recommends that an investigation should be made of the effect on accidonts and traffic flow of lighting other busy rural roads carrying fast traffic, including motorways. It also welcomes the arrangements now being made in Birmingham and other cities for further trial this winter of tho use of dipped headlights in all streets. The large-scalo road experiments, which are now an essential part of the Laboratory's rosearch, throw light on many problems of design which

* Department of Scientific and Industrial Research, Road Research 1963 :
The Report of the Road Research Roard with the Report of the Director of Road The Report of the Road Research Roard with the Report of the Director of Road
Tesearch. P1. vi $+168+12$ plates. (London: H.M. Stationery Office, 1964.) 11s. $6 d$. face the road engineer and which can be solved only from an oxamination of results obtained in the provailing conditions of traffic and climate. It is of the first importance that such experiments should be made and their performance recorded and assessed with a view to the earliest possible application of the results. A further investigation of the effect of frost on the performance of existing road pavements is to be made and a paper on the design of urban sewor systems was published, outlining the recommended procedures for the application of the new design method for surface water sewerage systems: more than a dozen applications have already boen received from Local Authorities in England.

The Board notes that the Department of Technical Co-operation has now decided to devote almost one-tenth of its research allocation to provide for the continuation of the activities of the tropical section of the Laboratory. These activities are dealt with more fully in an appendix to the report. They include further investigation of road-making materials from tropical countries with the object of expanding knowledge of overseas soils and of determining the causes of unusual properties, as well as a review of pavement design and soil-moisture movement in tropical and sub-tropical countries. The Board emphasizes the continuing need to make the Laboratory's work better known overseas, and it considers that the primary need in developing countries is knowledge of their own soils and of the other road-making materials available to them. The Board's own report includes the report of the Director of Road Research and appendixes giving dotails of the committees, staff and publications of the Station during the year. The activities of the Research Station on road systems and layout and parking needs have provided much of the fundamental information. required in planning for traffic in towns and olsewhere. Much attention is being given to safoty matters and for the first time for 10 years 1962 showed a significant decrease in the proportion of skidding accidents on wet roads. Prevention of some 2,000 accidents is attributed largely to the use of 'dead' rubber for tyre treads and of road materials with a high resistance to polishing under the action of traffic. Research on safety belts and harnesses continued along four main lines, including assistance to the British Standards Institution Committee on seat belts in the specification of a dynamic form of test for safety belts, studies of design, and performance surveys of the usage of the belt, and analyses of 